To the Editors:

\title{
Outcome of delayed allopathic management of orthopaedic injuries initially treated by traditional bone healers
}

\author{
Ceylon Medical Journal 2011; 56: 174-176
}

Non-allopathic treatment methods still play a substantial role in management of orthopaedic injuries in Sri Lanka despite the provision of free allopathic health care in state sector. Traditional healing ('deshiya chikithsa'/'Sinhala wedakama') has been practiced for centuries, well before the establishment of allopathic system [1]. These physicians are highly patronised on cultural background, thus treatment failures/complications may not be appreciated. As some of the traditional treatment methods contradict the lopathic management (AM) principles, a certain amount of mutual antagonism and distrust has been developed, which delays referrals from traditional bone healers (TBH) or patient return to $\mathrm{AM}$ after complications/failures of traditional treatment. The objective of this study was to analyze the functional outcome after delayed AM in a series of patients treated initially by TBH for orthopaedic injuries.

During this retrospective review, sixty nine consecutive patients who had delayed AM after TBH treatment, managed at a single orthopaedic unit at National Hospital of Sri Lanka from October 2009 to September 2010 were analysed. All patients had fractures/ dislocations. Patients treated with home remedies and patients who had soft tissue injuries were excluded. Operative/follow up records and a self-administered questionnaire provided the data. Among patients who were subjected to intervention, functional outcome was assessed by using a visual analogue score ranging from 0 to 10 after 2-4 months from treatment. During the assessment, upper limb functions affecting activities of daily living and the persons' profession was the main concern and independency for locomotion was the main concern in lower limb injuries. An outcome score above 6 was considered excellent, between 4-6 was satisfactory and below 4 was unsatisfactory.

Study population consisted of 38 females and 31 males. Median age was 52 (range 8-95) years. Forty four (64\%) patients had no school education or had primary education. Nineteen $(27.5 \%)$ and six $(8.5 \%)$ patients had completed secondary or tertiary education respectively. All had a government allopathic medical centre available within $5 \mathrm{~km}$. Fifty three $(77 \%)$ could reach a government base hospital armed by a consultant surgeon, within one hour of travelling. Majority (71\%) of the cohort initially believed that TBH treatment was better for orthopaedic injuries. This was further confirmed by $20(29 \%)$ having positive previous experiences. Cost of AM was the reason for two $(3 \%)$ patients to seek TBH treatment and unavailability of access to AM was not considered by anyone. Median delay prior to reaching AM was 2.5 months (range 3 days-3years). Non union (20), delayed union (18), vascular necrosis (9), malunion (8) and soft tissue infection (8) were the common complications at presentation to AM.

Table 1 summarises the management options and functional outcome. Thirty four and twenty three patients had excellent and satisfactory short term outcome. Treatment outcome was unsatisfactory in five cases. Seven patients were not intervened. Six of them had fractured neck of the femur complicated with grade 3 pressure sores, orthostatic pneumonia or urinary sepsis. One who had a flexed, ankylosed elbow due to non-reduced elbow dislocation could be intervened in the future when arthroplasty prosthesis becomes available in government hospitals.

Fracture treatment is rapidly evolving in allopathic orthopaedics and emphasis is on early mobilisation and rapid return to the home environment. Internal fixation is therefore becoming the preferred choice of treatment in dedicated centres but closed reduction and maintenance with external casting is also accepted. Radiographic imaging plays a vital role in achieving an anatomical reduction. Antibiotics, analgesics, vaccinations and rehabilitation methodologies synergistically improve the ultimate outcome. Despite the absence of such assisting modalities, non allopathic orthopaedic treatment is still accepted worldwide, commonly in developing countries. Published literature usually highlights the complications of native treatment methods [2-6].

Published studies highlight lack of availability and cost of AM as the two main determinants for the patients to consider TBH treatment $[4,5]$. In the current study these two factors had a minimal impact on the decision making possibly due to the provision of free health care by the State with a widespread network of allopathic medical centres in Sri Lanka. All patients had complications of the initial injury or previous treatment at the arrival to AM. Bonesetters' gangrene requiring proximal amputation and chronic osteomyelitis are highlighted in literature but the index cohort did not encounter such dreaded complications. Refusal of TBH to treat compound fractures and early return of patients to allopathic system in the presence of superficial infections can be considered as preventive factors. 
Table 1. Management options and functional outcome following allopathic management (mean value of visual analogue score is stated within parenthesis; score $>6$ Excellent, score between 4-6 Satisfactory, Score <4 Unsatisfactory; ORIF- Open reduction and internal fixation, MUA - Manipulation under anaesthesia)

\begin{tabular}{|c|c|c|c|c|}
\hline \multirow[t]{2}{*}{ Type of intervention } & \multicolumn{3}{|c|}{ Outcome } & \multirow[t]{2}{*}{ Total } \\
\hline & Excellent & Satisfactory & Unsatisfactory & \\
\hline Total hip arthroplasty * & $4(8)$ & $1(6)$ & - & $5(7.6)$ \\
\hline Hip hemiarthroplasty & $4(8.5)$ & $3(5.7)$ & - & $7(7.3)$ \\
\hline ORIF-femur & $2(8.5)$ & - & - & $2(8.5)$ \\
\hline Femur - reconstruction * & - & $1(6)$ & - & $1(6)$ \\
\hline $\begin{array}{l}\text { Tibial plateau fracture fixation } \\
\text { and anterior cruciate repair }\end{array}$ & $1(8)$ & - & - & $1(8)$ \\
\hline ORIF - tibia & $3(8.3)$ & $1(6)$ & - & $4(7.8)$ \\
\hline ORIF - bimalleolar fracture & $1(8)$ & $1(6)$ & - & $2(7)$ \\
\hline Arthrodesis of ankle * & - & $1(5)$ & $1(3)$ & $2(4)$ \\
\hline MUA - leg fractures & $1(7)$ & $1(6)$ & $1(3)$ & $3(5.3)$ \\
\hline Open reduction of shoulder * & $3(7.3)$ & $1(6)$ & - & $4(7)$ \\
\hline ORIF-humerus & $1(7)$ & - & - & $1(7)$ \\
\hline Corrective osteotomy - humerus * & $2(7)$ & $1(6)$ & - & $3(6.7)$ \\
\hline ORIF - radius and ulna & $5(8.4)$ & $1(6)$ & - & $6(8)$ \\
\hline Excision of head of radius * & $2(7)$ & $2(6)$ & - & $4(6.5)$ \\
\hline Excision of styloid of ulna * & $2(7)$ & $1(6)$ & - & $3(6.7)$ \\
\hline Proximal carpal excision * & - & $1(5)$ & - & $1(5)$ \\
\hline Arthrodesis of wrist * & - & $2(5)$ & 1(3) & $3(4.3)$ \\
\hline MUA - forearm fractures & $3(8.6)$ & $2(6)$ & - & $5(7.6)$ \\
\hline $\begin{array}{l}\text { Rehabilitation with physiotherapy, } \\
\text { occupational therapy and orthosis * }\end{array}$ & - & $3(5.3)$ & 2(3) & $5(4.2)$ \\
\hline Total & 34 & 23 & 5 & 62 \\
\hline
\end{tabular}

(*Alternative procedures carried out due to delay of presentation/complications of TBH treatment) 
Majority of the patients were subject to intervention with open surgical procedures. Some patients required alternative procedures due to the delay of presentation or complications of previous treatment. Despite such drawbacks due to late presentation or complications, mort of the study population had excellent or satisfactory functional outcome after delayed allopathic interventions.

\section{References}

1. Uragoda CG. A history of medicine in Sri Lanka - from the earliest time to 1948 (1987).

2. Onuminya JE. The role of the traditional bonesetter in primary fracture care in Nigeria. South African Medical Journal 2004; 94: 652-8.

3. Udosen AM, Otei OO,Onuba O. Role of traditional bone setters in Africa: experience in Calabar, Nigeria. Annals of African Medicine 2006; 5: 170-3.

4. OlaOlorun DA, Oladiran IO, Adeniran A. Complications of fracture treatment by traditional bonesetters in southwest Nigeria. Family Practice 2001; 18: 635-7.

5. Dada A, Giwa SO, Yinusa W, et al. Complications of treatment of musculoskeletal injuries by bone setters. West African Journal of Medicine 2009; 28: 333-7.

6. Onuminya JE, Onabowale BO, Obekpa PO, Ihezue CH. Traditional bonesetter's gangrene. International Orthopaedics (SICOT) 1999; 23: 111-2.

\section{J A S B Jayasundara ${ }^{1}$, C N Wijesundere ${ }^{1}$, D S de Alwis ${ }^{1}$, K M S Weerasinghe ${ }^{1}$, G L Punchihewa ${ }^{1}$}

${ }^{1}$ Orthopaedic Unit, National Hospital of Sri Lanka, Colombo.

Correspondence: JASBJ, e-mail: <bingumal@sltnet.lk>. Received 28 December 2010 and revised version accepted 1 June 2011. Competing interests: none declared. 